\title{
AC 2010-351: STUDENT PERCEPTIONS OF THE CIVIL ENGINEERING BODY OF KNOWLEDGE
}

Angela Bielefeldt, University of Colorado, Boulder 


\title{
Student Perceptions of the Civil Engineering Body of Knowledge
}

\begin{abstract}
It is of interest to determine how civil engineering students perceive the educational outcome requirements articulated in the American Society of Civil Engineers Body of Knowledge (BOK2). Therefore, freshmen and senior civil engineering (CVEN) students at the University of Colorado at Boulder (CU) were introduced to the BOK2 and asked for feedback. Students in a first year Introduction to Civil Engineering course were provided with the BOK in 2008 and 2009. They were encouraged to use the information on the first homework assignment to define civil engineering and the skills required to be a civil engineer. The students articulated which five skills and abilities they thought were the most important to be a civil engineer and three skill areas that were unique to civil engineering compared to other engineering disciplines. At the end of the semester the students were asked to comment on their personal strengths and weaknesses in regards to the outcome skills in ABET and/or the BOK2. In addition, 65 senior civil engineering students ranked the importance, curriculum weaknesses, and personal weaknesses in the BOK2 outcomes. The freshman and senior responses in regards to the most important skills were significantly different, with the exception of the relative importance of design and math. In addition, five senior civil engineering students mapped their personal course experiences to the BOK2. One student noted that the capstone design course alone covered 21 of the 24 BOK2 outcomes, indicating that a single course can achieve a wide range of objectives and one need not view the BOK2 outcomes as "course-by-course" requirements. However, the outcomes in the senior design course were somewhat dependent on the specific project and the individual students' role on the project. For example, a service learning project for a developing community achieved to some extent the globalization outcome that other students noted was lacking. This approach of using "rich" pedagogy and learning experiences will be necessary to achieve the requirements in the BOK2. Student feedback on the BOK2 may indicate where curriculum changes in a specific program are needed, and/or may be useful indicators of what aspects of the profession may be appealing to students who are underrepresented in civil engineering (females and minorities).
\end{abstract}

\section{Background}

The American Society of Civil Engineers developed a Body of Knowledge (BOK2) which defines the breadth and depth of knowledge, skills, and attitudes required to become a licensed, practicing professional civil engineer in the $21^{\text {st }}$ century. ${ }^{1}$ The BOK2 is rooted in a vision for preparing future engineers to benefit society via their practice of civil engineering in 2025 and beyond. $^{2}$ It is important that students who aspire to become civil engineers to understand the skills, knowledge, and attitudes that they will be expected to have when they enter the workforce. If students gain an early understanding of these issues they may either be more or less motivated to pursue a degree in civil engineering. For example, many students today in "Gen Net" are motivated by social good and wanting to make the world better; however, they often do not perceive that engineering is a way to achieve this goal. ${ }^{10}$ A career that benefits society has been found to be even more motivational to female and minority students. ${ }^{14}$ Parikh $^{9}$ determined that there are somewhat different motivators for students in different engineering majors; civil engineering students were not included in the previous study. 
Engineering in general and civil engineering in particular have aspirations to attract greater diversity, ${ }^{4,5}$ and therefore students' perceptions that could lead retention and/or leaving the major are important. Gender and ethnicity have been found to influence the motivational factors that lead students to select and persist in engineering majors. Based on the results from the extensive APPLES study, Atman and Sheppard ${ }^{8}$ reported that as seniors female engineering students placed greater importance on professional and interpersonal skills than men; specifically, leadership, performing in teams, communication, and public speaking. First year female engineering students were found to be less confident then their male peers on math and science abilities, but equally confident in professional and interpersonal skills ${ }^{8}$. Therefore, if female students see the value of professional and interpersonal skills in the careers of engineers they may feel more confident of their overall ability in engineering.

Many students also want their college experience to provide a broad experience that prepares them for a rich life. For these students, the rigid curriculum requirements in engineering can be discouraging and may lead them to select other majors. ${ }^{13,14}$ At the University of Colorado at Boulder (CU) our civil engineering (CVEN) B.S. degree of 128 semester credits is very restricted and technically focused, compared to average CVEN curricula nationwide. ${ }^{12}$ The $\mathrm{CU}$ CVEN degree contains no free electives; in contrast, nationwide average CVEN curriculum contain 3 credits of free electives ${ }^{12}$ and all other engineering majors at CU (aerospace, chemical, computer, electrical, environmental, mechanical) except architectural engineering allow at least 3 credits of free electives. All of the engineering majors at CU have only 18 credits of humanities and social science electives; well below the national CVEN average of 27 credits. ${ }^{12}$ In addition, the civil engineering degree at CU has only 6 credits of technical electives versus the nationwide average of $\sim 11$ credits. ${ }^{12}$ The CVEN faculty at CU have resisted curricular change to increase flexibility, frequently stating that the ABET accreditation ${ }^{3}$, BOK2 requirements, and/or complex nature of the civil engineering profession cannot be adequately taught in fewer required courses. If students are taught about these curriculum drivers they may feel somewhat less negative about the constrained curriculum, instead recognizing its value as strong preparation for a rewarding career.

The first goal of this project was to introduce the BOK2 to first year civil engineering students and determine what information they perceived as most important and/or motivational. The student responses were explored to determine if there were differences in student attitudes based on gender or ethnicity. One of the primary goals of the first-year Introduction to Civil Engineering (CVEN) course at $\mathrm{CU}$ is to teach students about the profession of Civil Engineering. Armed with this knowledge the students may be motivated to persist in a challenging major or may quickly realize that another major would better suit their career goals. Given these course goals, the BOK2 seemed an ideal resource to define civil engineering and inspire our next generation of professionals.

A second goal of the project was to contrast senior CVEN students' opinions on the importance of the various BOK2 outcomes with the first year students. A third goal was to determine how well the students felt their experiences at $\mathrm{CU}$ prepared them for the broad requirements of the CVEN profession and the level of achievement expectations of the BOK2. 


\section{Evaluation Methods}

To determine the attitudes of first year students, three sets of information were used. In the 1credit Introduction to Civil Engineering course that CVEN students at $\mathrm{CU}$ are required to take, the BOK2 and ABET criteria were provided to the students in 2008 and 2009. Then on the first homework assignment in the course students were required to: (1) define civil engineering, (2) list five most important skills and/or abilities to be a successful civil engineer, (3) list three skill areas unique to civil engineering compared to other disciplines, and (4) the steps required to become a licensed PE. The information from this assignment revealed student attitudes about civil engineering. The course included additional assignments on sustainability (2009 only), ethics, a team West Point Bridge Designer project, a curriculum plan to graduation at CU with a B.S. in CVEN, a paper on a significant event or structure related to civil engineering (such as the Three Gorges Dam, the flooding in New Orleans from hurricane Katrina, etc.), and a short summary of a professional society meeting that they attended (such as ASCE or AGC). In the final assignment of the semester the students wrote a reflective essay that instructed them to state whether or not they planned to remain a civil engineering major and why/why not. The students were also instructed to comment on aspects of civil engineering that did/did not appeal to them, and what skills and attributes per the ASCE Body of Knowledge and ABET were their strengths/weaknesses or things they did/did not enjoy. Information from these essays revealed student attitudes about CVEN that they learned from the BOK2 and throughout the semester.

To determine senior student attitudes and perceived fulfillment of the BOK2 outcomes during their undergraduate careers, two methods were used. First, in the CVEN senior capstone design course students were given a 1-page written survey on the outcomes in BOK2 at the end of the semester in 2009. These 68 students were either graduating or one semester away from graduation. They were selected to represent a population of students familiar with the CVEN curriculum at $\mathrm{CU}$. The survey included a table containing the $24 \mathrm{BOK} 2$ outcomes and the highest level of achievement statements applicable to each outcome for a B.S. degree. For example, for the first outcome the survey stated: "1. Mathematics. Solve problems in math through differential equations and apply this knowledge to the solution of engineering problems." Similar statements were provided for each of the 24 outcomes. The students were then asked to:

1) rank the 3 outcomes that you think are the most important

2) rank the outcomes that you think are the least important to your future CVEN career

3) rank the three outcomes that you feel you are the weakest at

4) rank the three outcomes that you think should receive more attention in the curriculum at $\mathrm{CU}$

Five seniors were asked to examine the BOK2 in more detail. These CVEN students were enrolled in the environmental engineering design capstone course in Spring 2008 and Spring 2009. In spring 2008 the two CVEN students were asked to read the BOK2 in detail and then indicate how their coursework fulfilled the BOK2. In spring 2009 the three CVEN students were given more explicit instructions to map their courses and extracurricular activities to the BOK2 outcomes and appropriate levels of achievement. These three CVEN students also filled out the BOK2 survey described above, and at the end of the assignment wrote about a half page on:

a) Was the BOK2 interesting to read?

b) What did you read in the BOK2 that surprised you about civil engineering? 
c) Do you think all civil engineering students should be required to read the BOK2? Why/why not?

d) What skills/attributes in the BOK2 would you like to learn more about?

\section{Results: First Year Students}

The basic demographics of students in this first year course are summarized in Table 1. Although the course is targeted to first year CVEN majors, some students who transfer into CVEN take the course later and some students who have not yet declared an engineering major also take the course.

Table 1. Demographics of students in first year civil engineering course at CU

\begin{tabular}{|c|c|c|c|c|c|}
\hline Year & \# students & \% female & \% first year & $\begin{array}{c}\text { \% CVEN } \\
\text { majors }\end{array}$ & $\begin{array}{c}\text { \% white, non } \\
\text { Hispanic }\end{array}$ \\
\hline 2008 & 56 & 18 & 86 & 79 & 91 \\
\hline 2009 & 78 & 17 & 65 & 53 & 81 \\
\hline
\end{tabular}

After the initial lecture on civil engineering, students were provided access to the BOK2 and ABET criteria to assist in completing the first homework assignment. The students were asked to list the five most important knowledge, skills, or abilities to be a successful civil engineer. The five skills that were most frequently reported in 2009 were: communication (69\%), ethics (63\%), teamwork (59\%), creativity (57\%), and design (54\%). Less than $35 \%$ of the students listed other skills. There was somewhat less consensus on the skill areas unique to civil engineering compared to other engineering disciplines. The most commonly cited unique CVEN skills were: project management (49\%), business and public administration (45\%), public policy (42\%), design in more than one civil engineering context (32\%), and breadth in four technical areas appropriate to civil engineering (30\%). Differences were not significant between demographic groups (male vs. female; white vs. Hispanic), although the small numbers of female and minority students make it difficult to identify statistically significant differences.

In the final reflective essay of the semester, the students were asked to state if they did or did not want to become a civil engineer. In both 2008 and 2009, 76\% stated an interest in pursuing civil engineering. Only 11 students declared as CVEN majors at the beginning of the semester in 2008/2009 no longer had an interest in the major at the end of the semester. These students were: 3 females, 1 Hispanic, 1 Asian-American, 5 white males, and 1 foreign student. A greater percentage of females $(20 \%)$ had lost interest in civil engineering compared to their white male peers $(10 \%)$. Statements from the students who planned to change their major out of CVEN are quoted in Table 2. Three of the 11 students were planning to change into other engineering majors (1 Hispanic male, 1 Asian male, 1 white non-Hispanic male), 2 into a humanities/social science major (1 female, 1 white non-Hispanic male), and the other 6 were unsure what major they might pursue. Eight of the 11 students noted that the ability to help people and society was an attractive feature of civil engineering. The "glamour" of the job was noted by one student as a pro and another as a con (versus other engineering majors). Two students noted that they liked math and science and their courses, but that the degree requirements in CVEN were too constrained. Math and writing were also cited as reasons to leave engineering and/or CVEN. Most of the cons noted by the students planning to change their major out of civil engineering 
were similar to concerns noted by other students who planned to remain in civil engineering. However, those choosing to stay generally had more positive points than negative points individually.

Table 2. Statements from 11 students planning to leave the CVEN major on its pros and cons [the gender/ethnicity of the student is noted in brackets; $\mathrm{M}=$ male, $\mathrm{F}=$ female]

Pros of CVEN
- The things that appeal to me are being involved in such a project that causes so much attention. I want to be a part of a team that has made a structure that blows people away $[\mathrm{M}]$

- you are able to work out in the field [M]

- freedom to design and fix a problem in the best way $[\mathrm{M}]$

- everything you do immediately has an effect on people [M]

Help people [8x]; examples:

- final products are amazing and the help they provide people with some of the most important needs. The positive impact a civil engineer can make is something I really like about the career. $[\mathrm{F}]$

- I wanted to help people in [developing] countries by building structures [Asian M]

- I would like to do something like the Engineers Without Borders are doing, and help others with my degree $[\mathrm{F}]$

- lifelong goal and passion to make the world a better place $[\mathrm{F}]$

- I love the civil engineering aspects that help communities that can't help themselves to better their lives [hispanic M]

- I do like the idea of helping others [M]

Cons of CVEN

- the education I would get with an Engineering track is very narrow and specific. I want a broader education, with English and history, where I actually get to choose some of my classes [F]

- Although the quality of the education cannot be questioned, it is not very student friendly. There is no room for personalization in the program, with some semesters not even allowing room for an approved elective. [M]

- design within realistic constraints; the [first year projects course] was extremely frustrating $[2 \mathrm{x} ; \mathrm{F}]$

- the amount of paperwork / writing [2x;M]

- a mistake in this field could cause catastrophic failure leading to many deaths. [2x M]

- I feel that becoming a civil engineer does not appeal to my personality. ... weaknesses include my difficulty in both calculus and physics. [M]

- the math required is hard/tedious [2x M]

- its not that high glamour of the engineering professions [Aerospace "better"; M]

- I do not find much interest in building bridges and buildings anymore as in doing mechanical or biomedical engineering. I want to invent things that can help [people] medically. [Asian M]

- working with the public [M]

- more of a hands on approach I would like to take towards engineering [planning to switch to mechanical engineering based on first-year projects course; hispanic M]

The students were asked to discuss the skills required of civil engineers per ABET and the BOK2 that were their personal strengths/weaknesses or things that they enjoyed/did not. The majority of the 2009 students $(48 / 71=68 \%)$ indicated that they enjoy teamwork and/or that it is one of their strengths; far fewer evidenced hesitation, concern, or dislike of teamwork $(10 / 71 ; 14 \%)$. 
For example, one student wrote: "Teamwork is one of my stronger points. I get along with most people and can usually do my part to help the team. Not only am I a team player, but I love being part of a team. The unity and shared joy with a success is much better when I did something as part of a team, and when I am struggling with something, it is comforting to have a team there to help." For the other skills and outcomes there was significantly less consensus among the students about personal likes/dislikes and strengths/weaknesses.

\section{Results from Senior Student Survey}

Some of the senior students did not follow the BOK2 survey instructions; 45 students ranked all 24 of the outcomes in question 1 and a few other students just checked items that were most important without assigning a rank. The total number of students who responded ranged from 65 for questions 1 and 2, down to 59 for question 4 . A formula was used to determine the highest ranked outcomes for each question: $\left(4 * \#\right.$ of $1^{\text {st }}$ ranks $)+\left(3 * \#\right.$ of $2^{\text {nd }}$ ranks $)+\left(2 * \#\right.$ of $3^{\text {rd }}$ ranks) + (\# of students who checked it without ranking). Results are summarized in Figure 1.

Figure 1. Summary of Senior CVEN Student Rankings of BOK2 Outcomes
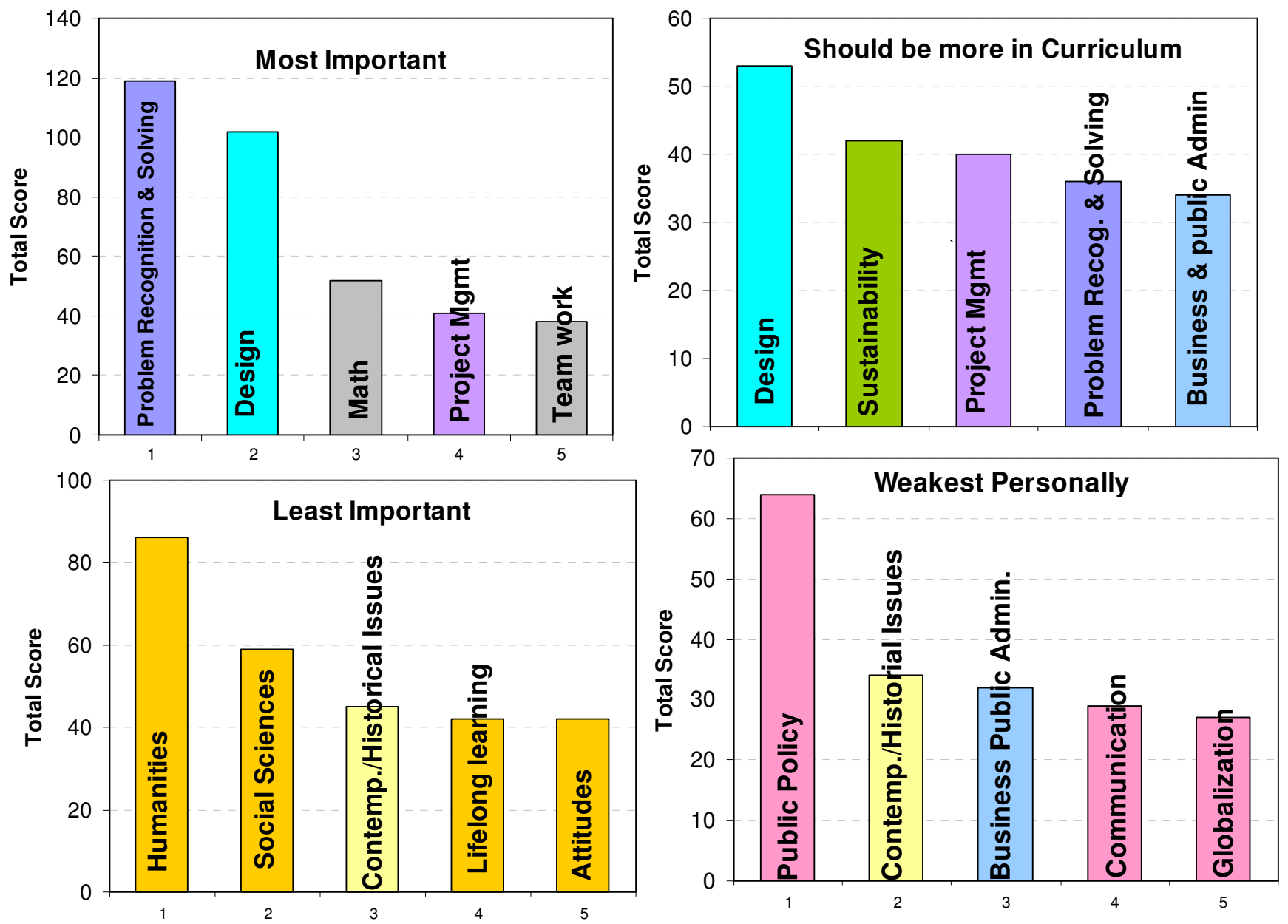
There was a clear difference in the outcomes that were ranked as most important. Five of the 24 outcomes were not rated in the top 3 by of any students (experiments, public policy, business and public administration, globalization, social sciences) while more than half of all of the students ranked problem recognition and solving and design as most important. Three of the 5 overall most important outcomes were also among the top five outcomes ranked by the students as needing more attention in the curriculum at CU (design, project management, problem solving). However, in general there was less consensus among the students about which outcomes should receive greater attention in their curriculum; the top 8 responses had between 25 and 53 points. As expected, there was no overlap between the outcomes ranked among the least and most important by the students; and none of the least important outcomes were among the items students most commonly cited as needing to receive more coverage in their curriculum.

The outcomes ranked personally weakest were very diverse, with 10 outcomes all receiving scores between 22 and 64 points. One outcome that garnered particularly diverse response was professional and ethical responsibility: ranked $8^{\text {th }}$ highest importance, $9^{\text {th }}$ highest least important, and $10^{\text {th }}$ highest should be more in curriculum. Differences in the student rankings for topics that needed more coverage in the curriculum and personal weaknesses may be due to individual differences in elective courses; it may be correlated with the specialization the student selected (such as structures vs. environmental); or may be influenced by demographic variables such as gender and race/ethnicity. However, this demographic information was not collected with the BOK2 survey that was given to the seniors.

There were some interesting insights gained through this exercise, in particular when compared to the five most important outcomes (unranked) by the first year students. This comparison is shown in Figure 2. Note that among the 65 survey responses from the CU CVEN seniors, $47 \%$ listed five most important skills, 5\% listed only four skills, $45 \%$ listed three skills, and 3\% only stated one most important skill. The data have been compared to the 160 senior engineering students in the APPLES study, who represented four campuses and were oversampled for underrepresented groups (the majors of these students are unknown). ${ }^{11}$

The first year students selected their top five most important skills for civil engineers based on a lecture that included the results from surveys of employers, reading the BOK2, reading the ABET accreditation criteria, and any prior knowledge of engineering that they had. The first year students' perceptions of importance aligned pretty well with the seniors in terms of design and math. However, the first year students assigned significantly more importance to communication, professional and ethical responsibility, and teamwork. The senior students were shown the same employer survey results as first year students, but they clearly realigned their perceptions of important skills for civil engineering on the basis of what was emphasized in the curriculum and/or internship experiences. The senior engineering student responses in the APPLES longitudinal study were similar to the CU CVEN seniors in the importance of problem solving and natural sciences, but more similar to the first year CU CVEN students for communication and teamwork skills. Note that in the APPLES survey students were provided a list of 20 skills/knowledge areas (which included creativity, engineering analysis, data analysis, engineering tools, and professionalism), while the CU seniors were provided the list of the 24 BOK2 outcomes. . 


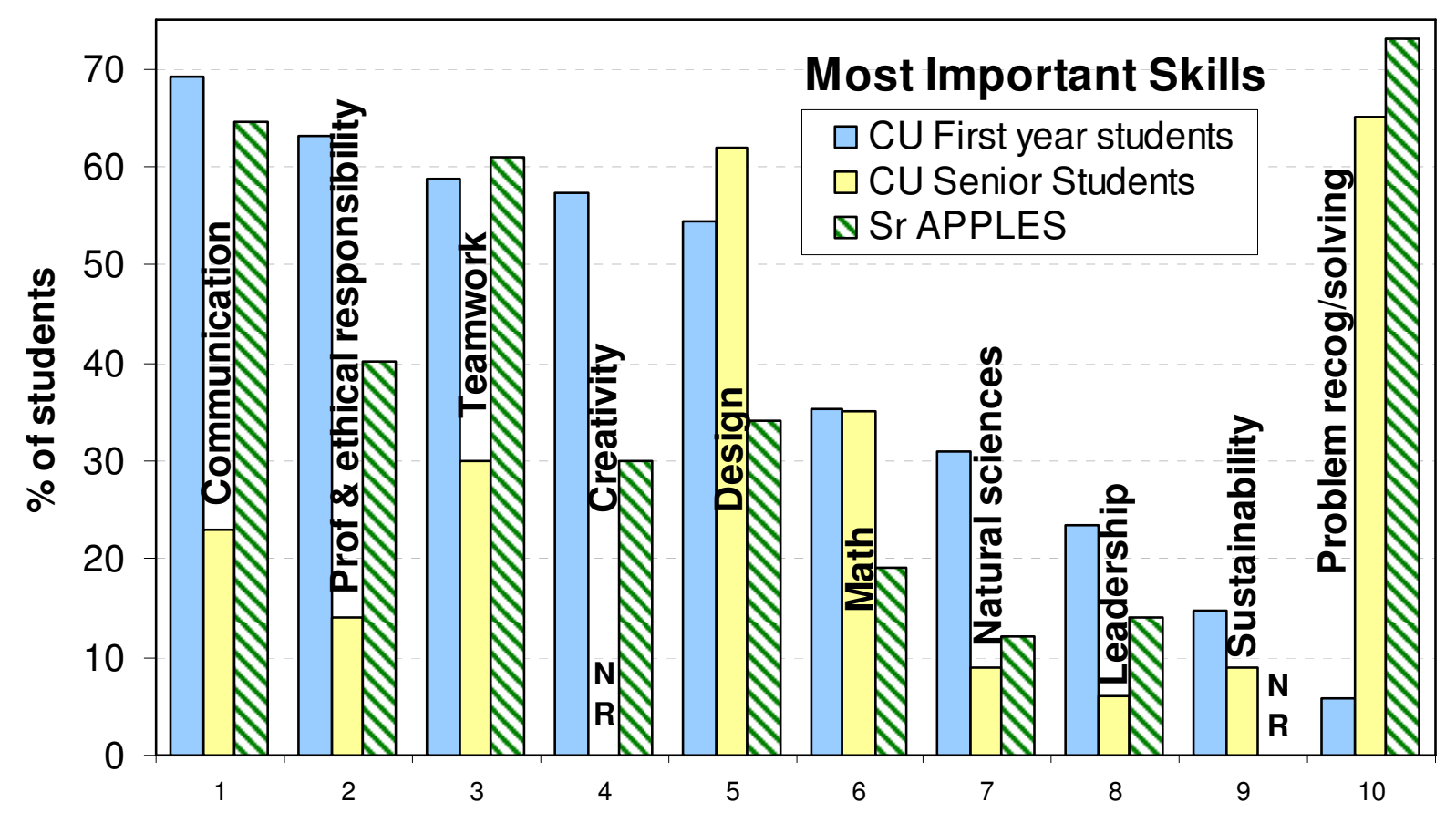

Figure 2. Comparison of the percentage of CU CVEN first year and senior students who indicated various skills in the top five most important for civil engineers compared to the percentages of engineering seniors from the nationwide APPLES study ${ }^{11}$. NR $=$ not ranked because the item was included in the list of outcome options ranked by the students.

\section{Detailed Comments from Senior Students}

Five senior civil engineering students enrolled in the environmental engineering capstone design course ( 3 females, 2 males) mapped their personal course experiences to the BOK2. Students A, $\mathrm{B}$, and $\mathrm{C}$ determined which outcomes and levels of achievement were fulfilled by various courses and extracurricular activities. Student D mapped all of her courses to the BOK2 outcomes, but did not directly incorporate the levels of achievement in her analysis. Student E only mapped the senior design course to the BOK2 outcomes and levels of achievement. Student E noted that three outcomes were unclear until she read the information in the Appendices of the BOK2: sustainability, globalization, and attitudes.

Student D identified two areas not included in her courses: globalization and life-long learning. The ratings of these two outcomes by the other students are summarized in Table 3. The other students believed that they had achieved these outcomes to varying extents based on courses and/or extracurricular activities. Students generally have a hard time determining the meaning of life-long learning, because this outcome is intended to be covered in multiple required courses (as expected due to accreditation requirements). Some of the students in the design course have worked on service learning projects for international communities, so the "global" experiences of individual students vary. Student D notes: "many of the major learning experiences of my college career (i.e. study abroad, internship, field courses) were experienced outside of the CVEN department, and many of these experiences were not recognized by the department as valuable and/or applicable, therefore I did not receive credit towards my degree, leading to an 
extra year of study". The importance of extracurricular experiences is acknowledged in the BOK2; however, Student D felt some of these experiences should receive course credit. Student D noted that the curriculum at our University highly emphasizes foundational and technical outcomes that are specific and narrow, with less attention to the professional outcomes and "human-based skills".

Table 3. Courses and activities that the senior students rated as fulfilling various levels of achievement for the Globalization and Lifelong Learning outcomes (extracurricular activities are shown in italics; superscripts identify different students)

\begin{tabular}{|c|c|c|c|c|}
\hline & \multicolumn{4}{|c|}{ Bloom's taxonomy Level of Achievement } \\
\hline Outcome & 1. Knowledge & 2. Comprehension & 3. Application & 4. Analysis \\
\hline $\begin{array}{l}\text { Global- } \\
\text { ization }\end{array}$ & $\begin{array}{l}1^{\text {st }} \text { year intro } \\
\text { Construction } \\
\text { Equip. \& }^{A t^{\circ}}{ }^{\mathrm{B}} \\
\text { EWB }^{B} \\
\text { Internship }^{B}\end{array}$ & $\begin{array}{l}\text { Senior Design }^{C} \\
\text { Applied Ecology } \\
\text { EWB }^{B} \\
\text { Internship }^{B}\end{array}$ & $\begin{array}{l}\text { Study Abroad } \\
\text { EWB }^{\mathrm{C}} \\
\text { Internship }^{B}\end{array}$ & $\begin{array}{l}\text { Sr Design }{ }^{A, C} \\
E^{B}{ }^{B} \\
\text { Internship }^{B}\end{array}$ \\
\hline $\begin{array}{l}\text { Life-long } \\
\text { learning }\end{array}$ & $\begin{array}{l}1^{\text {st }} \text { year intro } \\
\text { Indep. }^{A} \text { Research }^{B} \\
\text { EWB }^{B} \\
\text { Internship }^{B}\end{array}$ & $\begin{array}{l}\text { Sr Design } \\
1^{\text {st }} \text { year projects }^{\mathrm{C}} \\
\text { Intro Constr Mgmt }^{\mathrm{A}} \\
\mathrm{Water} \mathrm{\&} \mathrm{WW} \mathrm{Tmt}^{\mathrm{A}} \\
\text { Indep. Research }^{B} \\
\text { EWB }^{B} \\
\text { Internship }^{B}\end{array}$ & $\begin{array}{l}\text { Senior Design }{ }^{A, C} \\
\text { Constr. Equip \& } \mathrm{Mth}^{\mathrm{A}} \\
\text { Indep. Research }^{B} \\
\text { EWB }^{B} \\
\text { Internship }^{B}\end{array}$ & Internship ${ }^{A, B}$ \\
\hline
\end{tabular}

EWB = Engineers Without Borders student society

Table 4 summarizes the student ratings of how the senior design course fulfilled the BOK2 outcomes and levels of achievement (LOA) for each criterion. Student E mapped only the design course to the BOK2, while Students A, B, and C mapped the entire course curriculum to the BOK2 and therefore did not necessarily consider senior design exhaustively. For example, student $\mathrm{C}$ only listed a single course for each outcome LOA. Only 2 of 24 outcomes were rated by one or more students as not being addressed to at least some extent in the senior design course: mathematics and humanities. Mathematics was excluded, per the commentary of Student $\mathrm{E}$, due to the fact that she did not use math through differential equations on her design project. Eight outcomes were achieved to the desired bachelor's LOA; 12 outcomes may be achieved to a LOA beyond that required for the B.S. degree; and 2 outcomes were achieved to some extent but below that which is desired in a B.S. degree. This indicates that a single course can achieve a wide range of objectives and one need not view the BOK as a "course-by-course" requirement. But this may be somewhat dependent on the specific project selected and the individual students' role on the project. Students B and E served as the project manager for their teams, which likely increased their ratings of leadership and project management, compared to the experience of some other students in the same course. As another example, students A and C worked on a service learning project for a developing country, which achieved to some extent the globalization outcome that the other students found lacking.

The results of our mapping exercise are similar to the BOK2 outcomes fulfillment in ten different programs as reported by Fridley et al. ${ }^{7}$ The outcomes where more than half of the 
programs did not indicate that the target LOA at the Bachelor's level was achieved for all of the outcome by all of their B.S. graduates were: humanities, social sciences, sustainability, contemporary issues/history, risk \& uncertainty, public policy, business \& public administration, globalization, and leadership. Some of these are the same outcomes noted as weak in the capstone design course. A similar comparison curriculum-wide cannot yet be made since the CU seniors included all of their coursework rather than just their required courses in the mapping exercise, and the faculty have not yet mapped the LOA for all of the outcomes in the BOK2.

Table 4. BOK2 Outcomes with Levels of Achievement Desired at Bachelor's (B), Masters (M), or through Experience (E) compared to achievement in the Senior Design Course rated by the students shown as superscripts (and yellow shaded)

\begin{tabular}{|c|c|c|c|c|c|c|}
\hline \multirow[t]{2}{*}{ BOK2 Outcomes } & \multicolumn{6}{|c|}{ Level of Achievement } \\
\hline & 1 & 2 & 3 & 4 & 5 & 6 \\
\hline 1. Mathematics & $\overline{\mathbf{B}}$ & $\overline{\mathbf{B}}$ & $\overline{\mathbf{B}}$ & & & \\
\hline 2. Natural sciences & $\mathbf{B}^{\mathrm{E}}$ & $\mathbf{B}^{\mathrm{E}}$ & $\mathbf{B}^{\mathrm{E}}$ & & & \\
\hline 3. Humanities & $\mathbf{B}$ & B & B & & & \\
\hline 4. Social Sciences & $\mathbf{B}^{\mathrm{E}}$ & $\mathbf{B}^{\mathrm{E}}$ & $\mathbf{B}^{\mathrm{E}}$ & & & \\
\hline 5. Material science & $\mathbf{B}^{\mathrm{E}}$ & $\mathbf{B}^{\mathrm{E}}$ & $\mathbf{B}^{\mathrm{E}}$ & & & \\
\hline 6. Mechanics & $\mathbf{B}^{\mathrm{E}}$ & $\mathbf{B}^{\mathrm{E}}$ & $\mathbf{B}^{\mathrm{E}}$ & B & & \\
\hline 7. Experiments & $\mathbf{B}^{\mathrm{E}}$ & $\mathbf{B}^{\mathrm{E}}$ & $\mathbf{B}^{\mathrm{E}}$ & $\mathbf{B}^{\mathrm{E}}$ & $\mathrm{M}^{\mathrm{E}}$ & \\
\hline 8. Problem recognition and solving & $\mathbf{B}^{\mathrm{E}}$ & $\mathbf{B}^{\mathrm{E}}$ & $\mathbf{B}^{\mathrm{CE}}$ & $\mathrm{M}^{\mathrm{ACE}}$ & & \\
\hline 9. Design ${ }^{D}$ & $\mathbf{B}^{\mathrm{B}, \mathrm{E}}$ & $\mathbf{B}^{\mathrm{B}, \mathrm{E}}$ & $\mathbf{B}^{\mathrm{BCE}}$ & $\mathbf{B}^{\mathrm{BCE}}$ & $\mathbf{B}^{\mathrm{ABCE}}$ & $\mathrm{E}$ \\
\hline 10. Sustainability ${ }^{\mathrm{D}}$ & $\mathbf{B}^{\mathrm{BE}}$ & $\mathbf{B}^{\mathrm{BCE}}$ & $\mathbf{B}^{\mathrm{BCE}}$ & $\mathrm{E}^{\mathrm{A}}$ & & \\
\hline 11. Contemporary issues / hist. perspectives ${ }^{D}$ & $\mathbf{B}^{\mathrm{E}}$ & $\mathbf{B}^{\mathrm{E}}$ & $\mathbf{B}^{\mathrm{CE}}$ & $\mathrm{E}^{\mathrm{ACE}}$ & & \\
\hline 12. Risk and uncertainty & $\mathbf{B}^{\mathrm{E}}$ & $\mathbf{B}^{\mathrm{E}}$ & B & $\mathrm{E}$ & & \\
\hline 13. Project Management & $\mathbf{B}^{\mathrm{BE}}$ & $\mathbf{B}^{\mathrm{BE}}$ & $\mathbf{B}^{\mathrm{BCE}}$ & $\mathrm{E}^{\mathrm{ABE}}$ & & \\
\hline 14. Breadth in civil engineering areas ${ }^{D}$ & $\mathbf{B}^{\mathrm{E}}$ & $\mathbf{B}^{\mathrm{E}}$ & $\mathbf{B}^{\mathrm{E}}$ & $\mathbf{B}^{\mathrm{E}}$ & & \\
\hline 15. Technical specialization & $\mathbf{B}^{\mathrm{E}}$ & $\mathrm{M}$ & $\mathrm{M}$ & $\mathrm{M}$ & $\mathrm{M}$ & $\mathrm{E}$ \\
\hline 16. Communication ${ }^{\mathrm{D}}$ & $\mathbf{B}^{\mathrm{BE}}$ & $\mathbf{B}^{\mathrm{BE}}$ & $\mathbf{B}^{\mathrm{BCE}}$ & $\mathbf{B}^{\mathrm{BCE}}$ & $\mathrm{E}^{\mathrm{A}}$ & \\
\hline 17. Public policy ${ }^{\mathrm{D}}$ & $\mathbf{B}^{\mathrm{BE}}$ & $\mathbf{B}^{\mathrm{E}}$ & $\mathrm{E}^{\mathrm{A}, \mathrm{E}}$ & & & \\
\hline 18. Business and public administration ${ }^{\mathrm{D}}$ & $\mathbf{B}^{\mathrm{E}}$ & B & $\mathrm{E}^{\mathrm{A}}$ & & & \\
\hline 19. Globalization & $\mathbf{B}$ & $\mathbf{B}^{\mathrm{C}}$ & $\mathbf{B}$ & $\mathrm{E}^{\mathrm{AC}}$ & & \\
\hline 20. Leadership & $\mathbf{B}^{\mathrm{BE}}$ & $\mathbf{B}^{\mathrm{BCE}}$ & $\mathbf{B}^{\mathrm{BCE}}$ & $\mathrm{E}^{\mathrm{ABE}}$ & & \\
\hline 21. Teamwork ${ }^{\mathrm{D}}$ & $\mathbf{B}^{\mathrm{BE}}$ & $\mathbf{B}^{\mathrm{BE}}$ & $\mathbf{B}^{\mathrm{BCE}}$ & $\mathrm{E}^{\mathrm{AB}}$ & & \\
\hline 22. Attitudes & $\mathbf{B}^{\mathrm{BE}}$ & $\mathbf{B}^{\mathrm{ABCE}}$ & $\mathrm{E}$ & & & \\
\hline 23. Lifelong learning & $\mathbf{B}^{\mathrm{E}}$ & $\mathbf{B}^{\mathrm{E}}$ & $\mathbf{B}^{\mathrm{AC}}$ & $\mathrm{E}$ & $\mathrm{E}$ & \\
\hline 24. Professional \& ethical responsibility & $\mathbf{B}^{\mathrm{E}}$ & $\mathbf{B}^{\mathrm{E}}$ & $\mathbf{B}^{\mathrm{C}}$ & $\mathbf{B}^{\mathrm{C}}$ & $E^{A}$ & $\mathrm{E}$ \\
\hline
\end{tabular}

\section{Discussion and Summary}

First year students were informed about civil engineering using the BOK2 as one of many sources of information. This seemed to be a good method to teach students about the overall goals of the curriculum. Understanding these drivers may help reduce student displeasure with the overly constrained nature of the CVEN program at CU. For example, in a College-wide survey administered to first-year students in engineering at the beginning of their second 
semester, the top item that the CVEN students reported would make their experience in Engineering more satisfying was more free electives (64\%). CVEN students at CU have no free electives among the 128 credits. Emphasizing outcomes that are more appealing to female and minority students may help retain them in CVEN. However, more research is needed on the BOK2 and student attitudes to identify these aspects. Informing students early about the desired outcomes to enter professional practice may encourage them to seek out worthwhile extracurricular activities to achieve some of these outcomes, such as a study abroad experience or leadership in a student professional society. Three seniors all reported that these experiences led to higher levels of understanding for many of the BOK2 outcomes. As students gain a better understanding of the attributes desired for CVEN professionals, they will be better equipped to seek out experiences and courses to develop these skills.

Student opinions are of interest in determining what outcomes they perceive as being most important, and whether these outcomes are adequately addressed by the curriculum. In general, the outcomes rated as "least important" by the senior students have fairly minimal coverage in our current curriculum, although some confusion about the definitions of "lifelong learning" and "attitudes" may have contributed to low rankings of these outcomes by the students. Direct assessment of each of the 24 outcomes and related levels of achievement will be time consuming and require more than one evaluator to be valid. However, a first step in this process will start with the senior design reports and other course deliverables, and then determine which additional outcomes must be documented from other courses. Outcomes that are found to vary significantly across different projects may help identify desirable characteristics of senior design projects that are selected in future semesters.

\section{Bibliography}

1. ASCE (American Society of Civil Engineers). 2008. Civil Engineering Body of Knowledge for the $21^{\text {st }}$ Century. Preparing the Civil Engineer for the Future. Second Edition. ASCE. Reston, VA. www.asce.org

2. ASCE. 2007. The Vision for Civil Engineering in 2025. ASCE. Reston, VA.

3. ABET. 2008. Criteria for Accrediting Engineering Programs. Effective for Evaluations During the 2009-2010 Accreditation Cycle. ABET Engineering Accreditation Commission. www.abet.org

4. National Academy of Sciences, National Academy of Engineering, and Institute of Medicine of the National Academies. 2007. Rising Above the Gathering Storm: Energizing and Employing America for a Brighter Economic Future. The National Academies Press. Washington D.C. http://www.nap.edu/catalog/11463.html

5. Gibson, G.E., A. Davis-Blake, K.E. Dickson, and B. Mentel. 2003. Workforce Demographics among Project Engineering Professionals - Crisis Ahead? Journal of Management in Engineering. 19 (4), 173-182.

6. Welch, R., M. Robinson, C. Glagola, and J. Nelson. 2007. An Aspirational Vision for Civil Engineering in 2025: The BOK and Future Directions for Civil Engineering Curricula. ASEE Annual Conference and Exposition. Paper AC 2007-950.

7. Fridley, K., K. Hall, D. Larson, K. Sutterer, J. Alleman, K. McManis, J-P. Bardet, B. Gunnink, G. List, R. Smith, and T. Lennox. 2009. Educating the Future Civil Engineer for the New Civil Engineering Body of Knowledge. ASEE Annual Conference and Exposition. Paper AC 2009-752.

8. Atman, C. and S. Sheppard. 2009. Women in engineering: Interests, perspectives, confidence... and experiences. Presentation at the WEPAN National Conference, June 18.

9. Parikh, S., H. Chen, K. Donaldson, and S. Sheppard. 2009. Does major matter? A look at what motivates engineering students in different majors. ASEE Annual Conference and Exposition. Paper AC 2009-1304. 
10. Chubin, D., K. Donaldson, B. Olds, and L. Fleming. 2008. Educating generation Net - can U.S. engineering woo and win the competition for talent? Journal of Engineering Education, July, 245-257.

11. Atman, C. 2009. Educating the well-rounded engineer: Insights from the Academic Pathways Study. Frontiers in Education.

12. Russell, J.S. and Stouffer, W.B. 2005. Survey of the National Civil Engineering Curriculum. J. Prof. Issues in Engineering Education and Practice. 131 (2), 118-128.

13. Eibeck. P.A. 2009. Engineering Flexibility. Inside Higher Education. Dec. 4.

http://www.insidehighered.com/layout/set/dialog/views/2009/12/04/eibeck

14. Busch-Visniac, I.J. and Jarosz, J.P. 2004. Can diversity in the undergraduate engineering population be enhanced through curricular change? J. of Women and Minorities in Science and Engineering. 10, $255-281$. 